\section{Dinâmica do ataque de ATta SEXDENS \\ RUBROPILOSA FOREL, 1908 SOBRE A VEGETAÇÃO: USO DE MANIPULAÇÃO DE RECURSOS E ARMADILHA DE SOLO PARA SE ESTIMAR O COMPORTAMENTO DE FORRAGEAMENTO}

Marcelo Nivert Schlindwein*

\section{Introdução}

Um dos grandes problemas de se estudar saúvas é o seu comportamento complexo na escolha dos recursos que vão ser cortados. Já no fim do século passado (Belt, 1874; Bates, 1876), importantes naturalistas tentavam explicar a grande variedade de plantas atacadas por formigas cortadeiras. Na utilização do substrato vegetal para a criação do fungo, as saúvas (Atta ssp.) são altamente generalistas, podendo cortar quase $60 \%$ das plantas de um bosque tropical (Cherrett, 1968). Uma importante questão para o entendimento de como estes insetos sociais exploram o recurso é descrever como se dá os estímulos para cortar um determinado tipo de planta ou outro. Complementando esta questão avaliamos os fatores que levam as formigas a cortar uma árvore muito distante do ninho, tendo vários indivíduos da mesma espécie localizados bem mais próximo

Para tentar responder como estaria ocorrendo o processo de seleção das plantas, várias hipóteses foram elaboradas. Cherrett (1968) formulou a hipótese de que Atta cephalotes adotaria um sistema conservacionista de forrageamento, com o ataque diferenciado de plantas mais distantes do ninho, não atacando as plantas localizadas próximas, evitando desta forma que os recursos chegassem até o esgotamento. Um modelo alternativo (Fowler \& Stiles, 1980) sugere que as saúvas utilizam as manchas palatáveis dos recursos vegetais. $\mathrm{O}$ descobrimento e utilização destas manchas por meio de trilhas fisicas seriam os principais fatores que regulam a dinâmica de exploração dos recursos vegetais.

As saúvas utilizam uma área de forrageamento relativamente extensa,

* Doutor em Ciências Biológicas - Zoologia. Professor de Biogeografia e Zoologia do Centro Universitário de Araraquara - UNIARA. cortando uma grande diversidade de espécies vegetais (Cherrett, 1968; Vasconcelos, 1987, 1990; Schlindwein \& Fowler, 1999), e utilizam uma composição de plantas muito variável, tanto espacial como temporalmente (Howard, 1988). Os métodos de avaliação do forrageamento em Atta possuem muitas deficiências (Fowler et al., 1990), e ainda não há estudos suficientes para inferir como se dá a seleção das plantas (Bueno et al., 1990; Howard, 1990, 1991).

O forrageamento de saúvas é uma na exploração em escala (quantitativa e qualitativa) dos recursos, como resultado da interação de comportamentos individuais das operárias e a construção de trilhas de exploração. O forrageamento é regulado pelas respostas homeostáticas do fungo simbionte que irá processar a vegetação explorada. Portanto, o comportamento de ataque às plantas é bastante complexo (Vasconcelos, 1990). Os estudos realizados para se avaliar as estratégias e comportamentos das cortadeiras no campo (Fowler \& Robinson, 1979; Shepherd, 1982; Forti, 1985; Vasconcelos; 1987; Schlindwein, 1991; Schlindwein \& Fowler, 1999) mostraram uma grande variabilidade no uso dos recursos disponíveis na área, bem como a intensidade de exploração destes ao longo do tempo. $O$ encontro de novos recursos é um dos aspectos menos estudados da ecologia de forrageamento de saúvas (Fowler \& Robinson, 1979; Shepherd, 1982, 1985; Forti, 1985; Therrien \& Mcneil, 1990). A exploração começa a partir da identificação de um recurso utilizável pela colônia é que se inicia todo o processo de exploração deste. Entender como este comportamento de encontro das manchas utilizáveis resulta no uso de determinada planta, a partir da distribuição espacial, e como o efeito da distância do ninho e dos olheiros afeta a dinâmica de exploração dos diferentes recursos vegetais existentes, são questões básicas para se entender a dinâmica de forrageamento em saúvas.

A atividade de exploração das operárias foi avaliada, comparando entre um modelo onde as formigas realizam uma exploração "racional" dos recursos vegetais (modelo de conservação de Cherrett, 1968) e outro onde a exploração se processa pela identificação de manchas palatáveis de Fowler \& Stiles (1980), este, baseado no modelo clássico de dieta ótima (Macarthur \& Pianka, 1966). A partir da dinâmica de ataque a um conjunto de mudas de Citrus sinensis foi estudado como a distribuição espacial dos recursos afeta o padrão de exploração de $A$. sexdens rubropilosa, utilizando como principais parâmetros as distâncias entre as plantas transplantadas dos ninhos e olheiros e a distribuição espacial das operárias capturadas em armadilhas de solo.

\section{Material e métodos:}

Área de estudos

Foi utilizada uma área localizada no Campus da Unesp-Rio Claro, SP, 
Brasil (250,25'S e 47033’O, $612 \mathrm{~m}$ acima do nível do mar). O clima desta área se caracteriza por um período chuvoso englobando os meses de verão (dezembro a março) e um período de seca nos meses de inverno. A vegetação do local é do tipo "campo sujo" (Goodland \& Ferri, 1979). No período de 1989-1994, esta área sofreu incêndios anuais, restaram poucos arbustos intactos e o solo ficou praticamente sem cobertura vegetal. A área experimental foi dividida em duas parcelas de $352 \mathrm{~m}^{2}$ (parcelas I e II), separadas em cerca de 45 metros uma da outra, sendo que ambas possuíam as mesmas características gerais de vegetação, antes e depois dos incêndios. Na área foi encontrado um ninho ativo de $A$. sexdens rubropilosa, localizado a noroeste, distante aproximadamente cerca de 50 metros da parcela I e praticamente à mesma distância da parcela II. O ninho tinha aproximadamente $12 \mathrm{~m}^{2}$ de terra solta sobre o murundu (4 metros de comprimento por três metros de largura no sentido norte-sul). Também foi encontrado um segundo ninho, que possuía cerca de $24 \mathrm{~m}^{2}$ de terra solta (6 metros de comprimento por 4 de largura no sentido norte-sul). Neste segundo ninho, considerado inativo, não havia terra solta recente e não foi observada atividade nos olheiros durante o experimento

Em cada parcela uma malha de 11 por 16 pontos foi demarcada, com intervalos de 2 metros. Em 23 de outubro e 10 de setembro de 1993 foram mapeados os olheiros ativos e as trilhas. Este mapeamento constituía de marcação em papel milimetrado da posição das trilhas e dos olheiros e foi realizado até que a cobertura vegetal permitiu o encontro destes nas parcelas

Em cada ponto foi colocada uma armadilha de solo - "pitfall trap" (Southwood, 1978), que se constituía de um tubo de PVC de aproximadamente 20 $\mathrm{cm}$ de comprimento, que era introduzido no solo e no seu interior era colocado um tubo de ensaio plástico de cerca de $12 \mathrm{~cm}$ de comprimento (Majer, 1976). Esses tubos de ensaio foram preenchidos cerca de $1 / 3$ de seu volume com uma solução preparada de $25 \mathrm{ml}$ detergente neutro e $1000 \mathrm{ml}$ de água. As armadilhas foram deixadas nos plotes de estudo por um período de 72 horas em cada amostragem. Cada armadilha de solo foi etiquetada com suas coordenadas da parcela. Foram realizadas 10 amostragens no plote I, e 06 amostragens no plote II. O material foi posteriormente triado no laboratório. As operárias de $A$. sexdens rubropilosa foram medidas, utilizando-se a largura máxima da cabeça (Wilson, 1980).

Foram analisadas com regressões lineares as capturas de formigas e as classes de distância do ninho, após estandardizar os dados pelo número de armadilhas em cada classe de distância. Para minimizar o efeito da eventual presença de um olheiro ou de uma trilha foi descartado o maior valor de captura em cada classe de distância

Em 26 de novembro de 1993, após terem sido realizadas 4 amostragens com armadilhas de solo, foram transplantadas 15 mudas de Citrus sinensis var. valência com aproximadamente 1,5 metros de altura no plote I. As mudas foram transplantadas no centro dos quadrados de 2 metros entre os pontos das malhas de armadilhas de solo. Os locais onde as mudas foram plantadas foram escolhidos por sorteio através da retirada de pedaços de papel com o número de cada quadrado.

As folhas das mudas foram inspecionadas diariamente nos primeiros quatro meses de observação e em intervalos de no mínimo de 04 dias até ocorrência do próximo incêndio que ocorreu na área, em agosto de 1994. Foram registrados os ataques às folhas; a intensidade destes ataques; e o tempo transcorrido para ocorrer a desfolha total da muda. Este procedimento se dava pela inspeção das folhas de cada muda entre 8:00 e 9:00 horas da manhã e entre 17:00 e 18:30 horas. Foram realizadas observações noturnas (entre 20:00 e 3:00 horas), onde cada muda também tinha suas folhas avaliadas e a atividade observada. Qualquer corte nas folhas foi registrado, bem como quando o tempo para ocorrência da desfolha total. Quando a atividade de corte era concomitante a observação, este foi acompanhado até a desfolha total da muda.

A relação entre a distância do ninho e o número de dias para ocorrer o primeiro ataque foi analisada por regressão linear. Esta análise também foi efetuada para a distância do ninho e o número de dias para que a planta fosse completamente desfolhada. Para estas regressões foram incorporados testes de normalidade, significância, e análise de resíduos (teste de Durbin-Watson) (Sokal \& Röhlf, 1995). Os resultados foram plotados os intervalos de confiança de 95\%. Também foram utilizadas regressões múltiplas (Sokal \& Röhlf, 1995) para se avaliar os efeitos conjugados da distância do olheiro e conjugado com a distância do ninho para o primeiro ataque e o tempo ocorrido para a desfolha total da muda.

\section{Resultados e discussão}

Foram coletadas nas armadilhas de solo 450 formigas de $A$. sexdens rubropilosa (244 no plote I e 206 no plote II, Figura 1). As médias do tamanho das operárias não foram significativamente diferentes nos dois parcelas (parcela I: $\mathrm{c}=1.89 \mathrm{~mm}$, d.p. $=0.725$; parcela II: $\mathrm{c}=1.92 \mathrm{~mm}$, d.p. $=0.641 ; \mathrm{F}=0,1786 \mathrm{p}=0.67$; teste de homogeneidade de variâncias Bartlet $\mathrm{p}=0.151)$.O número de operárias nas armadilhas de solo diminui com o tempo de amostragem e eventual complexidade da paisagem, nas duas parcelas. No plote II, a diminuição de captura foi mais acentuada, e, no plote I, o número de operárias coletadas declinou nos 3 primeiros meses de 80 para 15 operárias.

Todas as regressões lineares e relacionando a distância do murundu principal e dos olheiros em relação ao ataque às mudas e sua desfolha total se mostraram positivas (Figuras 2; 3; 4 e 5). $\mathrm{O}$ fator da distância das mudas explica boa parte do ataque destas pelas operárias, tanto quanto ao seu 
descobrimento, como para sua utilização pelo ninho. A relação entre a distância do ninho e o tempo para que ocorresse desfolha total $\left(r=0.6977 ; r^{2} 0.344\right.$; Figura 4), e distância do olheiro ativo mais próximo e o tempo para ocorrer desfolha total $\left(\mathrm{r}=0.631 ; \mathrm{r}^{2}=0.398\right.$; Figura 5) mostra que as operárias encontram e exploram os recursos que estejam mais próximos do ninho e dos olheiros.

Tanto o ataque como a desfolha indicam uma relação direta com a distância do ninho e a proximidade dos olheiros ativos. A análise da relação entre as observações em que as folhas se encontravam intactas, isto é, sem cortes nas mudas, e a distância ao ninho também mostrou uma leve tendência das plantas serem mais atacadas em distâncias mais próximas ao ninho ( $\mathrm{r}=0.531$, $\left.\mathrm{r}^{2}=0.287\right)$.

Não ocorreu diferença significativa na captura de operárias nas armadilhas de solo que estavam localizadas próximas das mudas antes da introdução das mesmas $(\mathrm{F}=0.3685 ; \mathbf{p}=\mathbf{n} . \mathbf{s}$., coleta setembro $\mathbf{A})$. Com o transplante das mudas a captura de operárias foi significativamente maior nos pontos localizados nos quadrados ao redor das mesmas $(\mathrm{F}=4.068 ; \mathbf{p}<\mathbf{0 . 0 5}$; análise realizada para coleta outubro B). Portanto, a introdução das mudas levou a uma maior captura proporcional em armadilhas localizadas nas armadilhas de solo localizada próximas das mesmas.

Das 15 mudas, $66,66 \%$ foram desfolhadas no mesmo dia em que o primeiro ataque foi em observado (Spearman $\mathrm{r}=0.971$ ). As mudas eram exploradas de tal forma que em cerca de dois dias após o primeiro ataque estas estavam completamente desfolhadas. Todavia, ocorreu um grande período de tempo entre o primeiro corte e a desfolha total de algumas mudas (até 124 dias). A partir do momento em que era estabelecido um fluxo contínuo de operárias todas as mudas foram sempre completamente cortadas, com as pontas de galhos verdes podadas. Esse fluxo contínuo era formado quando a exploração passava, de um grupo de três ou quatro operárias que praticamente efetuavam o corte e transporte de maneira sincronizada, indo e voltando em conjunto, para um fluxo de chegada intermitente de operárias. $\mathrm{O}$ mesmo acontecia no caso da desfolha realizado pela segunda ou, mais vezes. Isto parece depender da capacidade da operária exploradora, que efetua o corte de reconhecimento. E que, ao levar o fragmento ao ninho, faz com que mais operárias voltem e iniciem o forrageamento, estabelecendo o recrutamento.

De um modo geral, após o começo do forrageamento intensivo sobre as mudas este não era interrompido até o esgotamento do recurso. Nas observações diretas, mesmo durante uma chuva intensa ou brusca queda de temperatura, o corte da muda não cessava até que as folhas fossem completamente recortadas e recolhidas no solo.

A hipótese de conservação de Cherrett (1968) não foi confirmada pelos dados. $\mathrm{O}$ corte teve uma forte relação espacial à distância do ninho. Certos dados obtidos (124 dias para cortar uma muda, enquanto a muda mais próxima, a cerca de 2 metros de distância, era constantemente recortada durante este período), poderiam ser interpretados como resposta conservativa. Porém, as observações do comportamento de desfolha e primeiro ataque dão muito mais consistência à interpretação de que as formigas não utilizam os recursos não identificados como utilizáveis dentro do mosaico da vegetação. A alta porcentagem de resposta primeiro-ataque/desfolha (maior nas proximidades do ninho) poderia ser interpretada como resposta típica de um herbívoro oportunista (Shepherd, 1982). A. sexdens rubropilosa estaria adaptada a condições naturais com mosaicos complexos de plantas, com as quais tiveram um longo processo coevolutivo, onde estaria baseada sua estratégia conservativa (Cherrett 1983). Ambientes simplificados e com plantas sem os padrões aleloquímicos decorrentes do jogo evolutivo não poderiam gerar respostas conservativas. $\mathrm{O}$ manejo conservativo só funcionaria dentro de padrões naturais, com sua inerente complexidade de vegetação (Cherrett 1983). A distribuição das operárias capturadas nas armadilhas nas diferentes distâncias do ninho pode indicar que, numa escala curta de tempo, A. sexdens rubropilosa executa o modelo de encontro e consumo de recursos por dieta ótima (Fowler \& Stiles, 1980). Porém, ao longo do tempo, a estratégia de distribuir operária pode levar a uma estratégia conservativa, pois as plantas mais próximas ou mais distantes do ninho podem corresponder aos locais explorados pelas operárias em busca de recursos.

Os dados obtidos concordam com Shepherd (1982), que utilizando manipulação de recursos na Costa Rica, também notou o efeito da distância destes ao ninho. Este autor definiu as cortadeiras dentro do conceito de predadores oportunistas (Maynard-Smith, 1978). À distância do ninho determina a intensidade com que os recursos são explorados, sendo que uma menor atividade de exploradoras foi detectada em relação a distância do ninho.

$\mathrm{Na}$ faixa de distância entre 65 e 85 metros, poucas armadilhas (uma ou duas, geralmente) foram responsáveis pelo total das operárias coletadas, enquanto nas distâncias menores muitas armadilhas capturavam poucas operárias. Isto parece concordar com estudos onde olheiros ativos se distribuem em maior densidade nos plotes próximas ao ninho (Amante, 1972). Em estudo anterior em área próxima a esta (cerca de 300 metros), observou-se um padrão semelhante, com plantas atacadas em maior intensidade na faixa de 40 a 70 metros do ninho (Schlindwein, 1991).

As regressões múltiplas mostraram que à distância do ninho foi o fator ou cofator mais importante para o primeiro ataque às mudas $(\mathrm{r}=0.9398$, $\left.\mathrm{r}^{2}=0.8831, \mathrm{~b}_{\text {ninho }}=0.721, \mathrm{~b}_{\text {olheiro }}=0.305\right)$, fato que não ocorreu para a desfolha a distância do olheiro $\left(r=0.748, r^{2}=0.5990, b_{\text {ninho }}=0.748, b_{\text {olheiro }}=-0.170\right)$. Pode se inferir que a não ocorrência de trilhas físicas nesta área impediu que se 
pudesse testar o efeito destas sobre a exploração dos recursos como realizado por Fowler \& Robinson (1979). No modelo destes autores a escolha dos recursos partia destas trilhas. Neste experimento só foi possível testar a distância do ninho, com resultados bastante significativos.

Dentro da escala estudada, o modelo de manchas palatáveis (Fowler \& Stiles, 1980) melhor explica os padrões encontrados. As saúvas se apresentam como predadores oportunistas, onde, após identificarem a fonte, imediatamente realizam a exploração da mesma. $\mathrm{O}$ encontro das plantas mais próximas ao ninho (Delabie et al., 1993) pode ser uma resposta ao menor gasto energético de se explorar essas áreas mais próximas e do menor custo para se efetuar o corte e transporte desse material para o ninho (Schoener, 1971; Howard, 1991)

\section{Conclusões}

a) Foi a localização espacial dos recursos vegetais que determinou a intensidade de atividade de exploração

b) A partir da recuperação da vegetação da área após o incêndio, as armadilhas de solo foram menos eficientes para detectar a atividade das formigas.

c) Baseado na maior relação entre distância e exploração dos recursos vegetais o modelo de manchas palátaveis é o que melhor se enquadra dentro das observações realizadas. $\mathrm{O}$ modelo de conservação não foi adequado para o forrageamento observado, nesta escala espaço-temporal.

FIGURA 1. Operárias capturadas nas armadilhas de solo nos dois plotes estudados

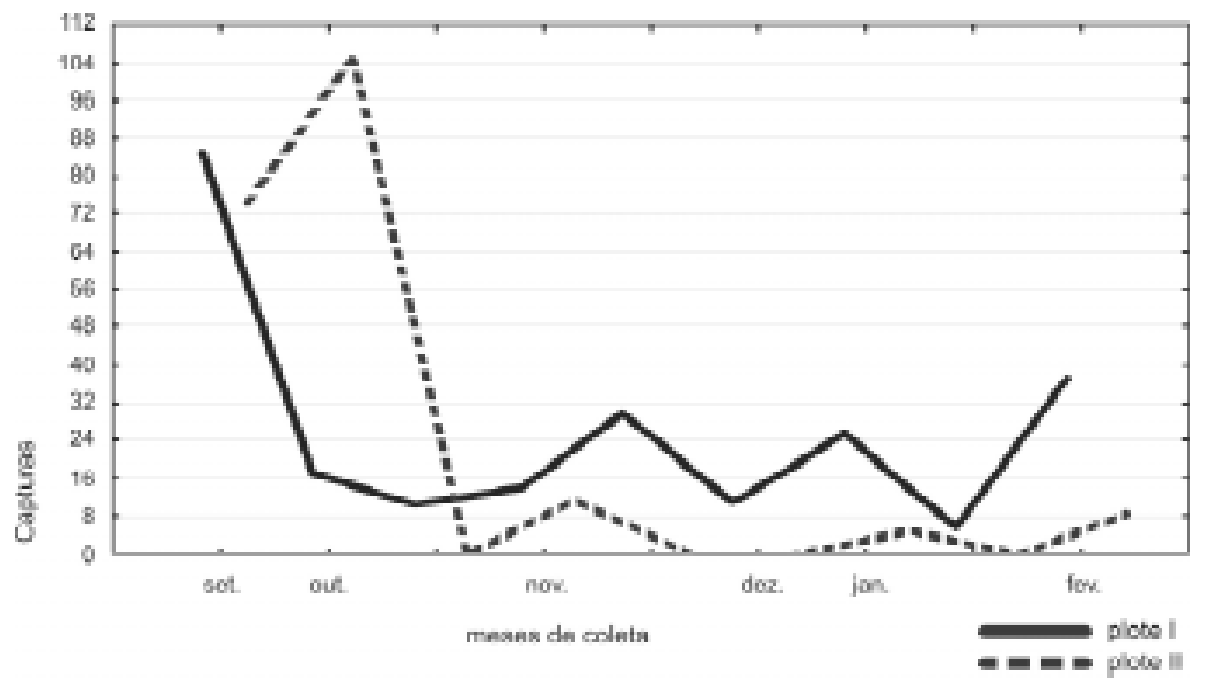

FIGURA 2. Regressão entre o primeiro ataque e a distância ao olheiro ativo. $\mathrm{Y}=-9.708+11.346 * \mathrm{x}(\mathrm{r}=698 ; \mathrm{r} 2=0.486)$.

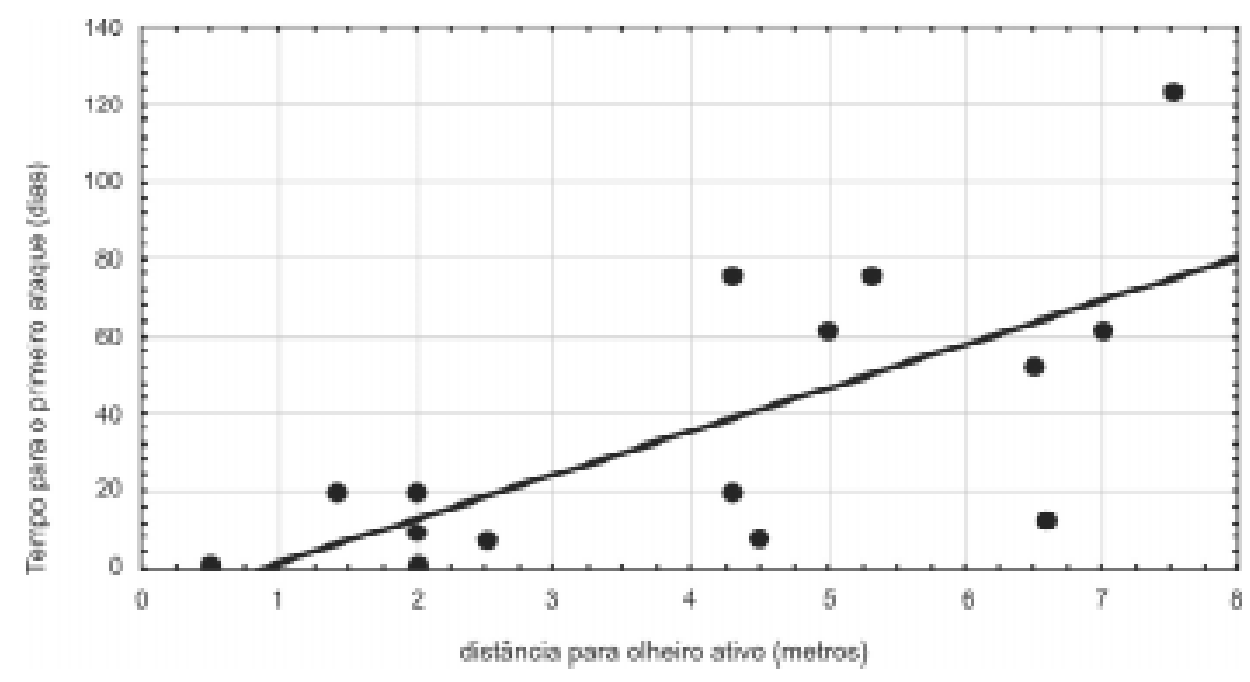

FIGURA 3. Regressão entre a desfolha total e a distância do olheiro ativo. $Y=-.9607+11.310 * x(r=631 ; r 2=0.398)$.

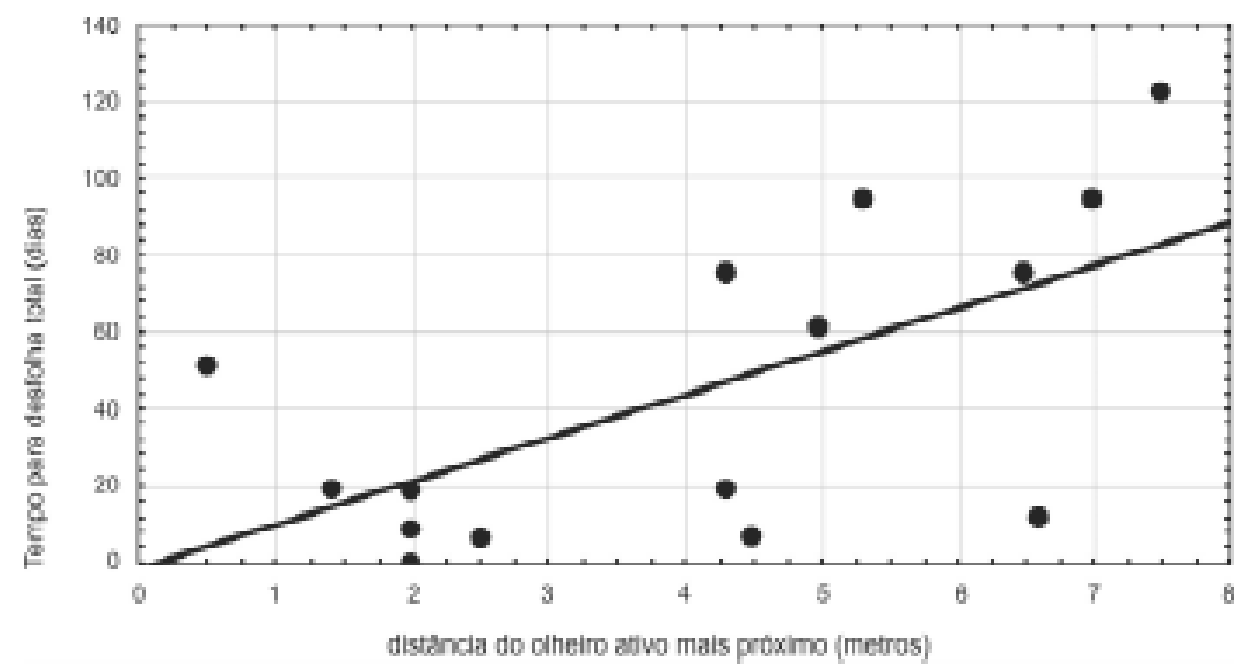


FIGURA 4. Regressão entre a distância do murundu e o tempo para desfolha das mudas. $\mathrm{Y}=-442.0+7.9956 * \mathrm{x}(\mathrm{r}=58 ; \mathrm{r} 2=0.344)$

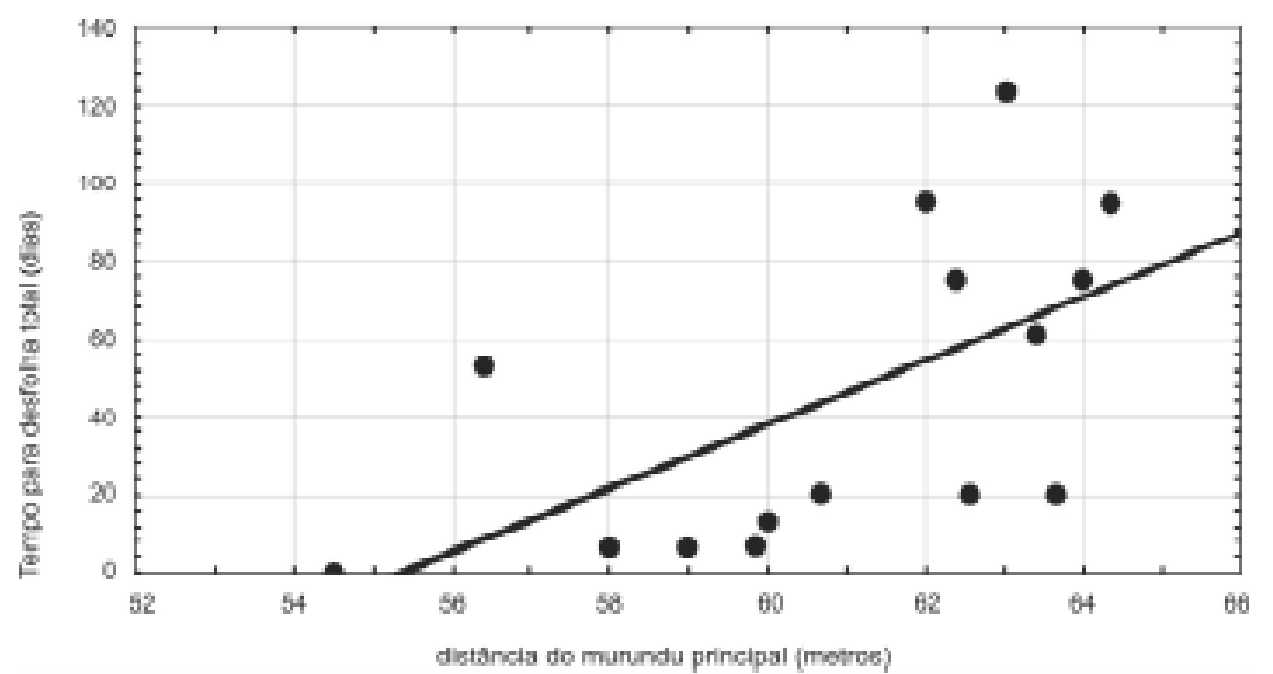

FIGURA 5. Regressão entre a distância do murundu e o primeiro ataque $\mathrm{Y}=-473.8+8.3773 *_{\mathrm{x}}(\mathrm{r}=0.678 ; \mathrm{r} 2=0.398)$.

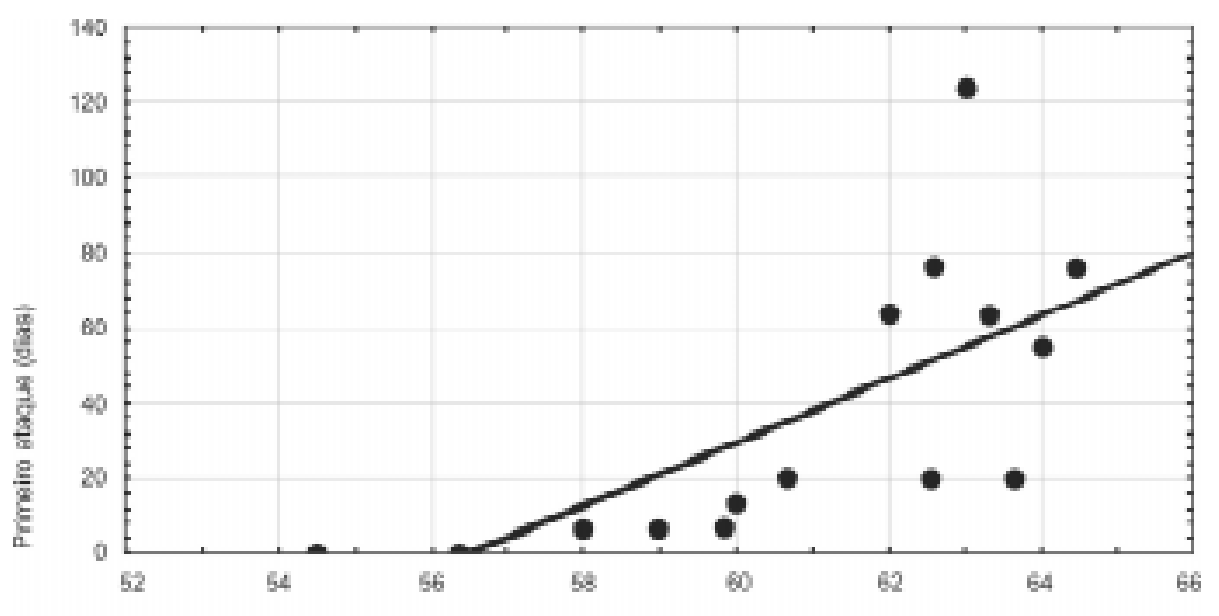

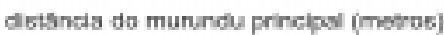

\section{Agradecimentos}

Este trabalho foi financiado por uma Bolsa de Doutoramento do CNPq. $\mathrm{O}$ autor agradece à Harold Gordon Fowler (orientador), Teresinha Della-Lucia, Virgílio Pereira-da-Silva, Luís Carlos Forti, Odair C. Bueno, Maria José HeblingBeraldo pelas valiosas críticas e sugestões ao trabalho. Às estagiárias Andrea Bossi, Mônica Mastroiani e Valéria Janny pela colaboração com as armadilhas de solo.

Referências bibliográficas:

BATES, H.B. The naturalist in amazon river. London: Jonh Murray. 1876. p.301.

BELT, T. The naturalist on nicaragua. London: E. Bumpus. 1874. p.300.

BUENO, O.C.; HEBLING-BERALDO, M.J.A.; AULINO-DA-SILVA, O. PAGNOCCA, F.; FERNADEZ, J.B.; VIEIRA, P.C. Toxic effects of plants on leaf-cutting ants and their symbiotic fungus. In: VAN DE MEER, R.K.; JAFFÉ, K.; CENDEÑO, A. (Eds.). Applied mymercology: a world perspective, Boulder: Westview Press,. p.420-426. 1990.

\section{CARVALHO, M.P.; SCHLINDWEIN. M.N.; FOWLER, H.G.}

Experimentos de campo em A. sexdens rubropilosa utilizando mudas exóticas e nativas. In: ENCONTRO DE MIRMECOLOGIA, 12, São Leopoldo. Resumos. São Leopoldo. p.76. 1995.

CHERRETT, J.M. The foraging behavior of Atta cephalotes (Hymenoptera: Formicidae) - Foraging parttern and plant species attacked in tropical rainforest. J. Anim. Ecol. v.37, p.387-403. 1968.

CHERRET, J.M. Resource conservation by the leaf-cutting ant Atta cephalotes in tropical rain forest. In SUTTON, S.L.; WHITMORE, T.C.; CHADWICK.. Tropical rain forest: ecology and management. Oxford: Blackwell Scientific publications,. p.253-263. 1983.

DELABIE, J.H.C.; ENCARNAÇÃO, A.M.V.; CAZORLA, I.M. Impact d'une fourmilière d'Atta cephalotes (Formicidae: Attini) sur une cacaoyère en formation. Act. Coll. Ins. Soc. v.8, p.63-70. 1993. 
FORTI, L.C. Ecologia da saúva Atta capiguara Gonçalves 1944

(Hymenoptera: Formicidae) em pastagem. Tese (Doutorado) - ESALQ, USP, Piracicaba, 1985. p.235.

FOWLER, H.G.; , ROBINSON, S.W. Foraging by Atta sexdens (Formicidae: Attini) seasonal patterns, caste and efficiency. Ecol. Entomol., v.4, p.239-247, 1979.

FOWLER, H.G.; STILES, E.W. Conservative foraging by leaf-cutting ants? The role of foraging territories ands trails and environmental patchiness. Sociobiology v.5, p.25-41, 1980.

FOWLER, H.G.; FORTI, L.C.; Di ROMAGNANO L.F.T. Methods for the evaluation of leaf-cutting ants. In: VAN DE MEER, R.K.; JAFFE, K.; CENDEÑO, A. (Eds.). Applied mymercology: a world perspective Boulder: Westview. p.228-241. 1990.

GOODLAND, R.; FERRI, M.G. 1979. Ecologia do cerrado. São Paulo: Edusp. p.193.

HOWARD, J.J. Leaf-cutting ant selection: the effect of nutrients water, and secondary chemistry and physical features. Ecology v.68, p.503-515. 1987.

HOWARD, J.J. Leaf cutting and diet selection: relative influence of leaf chemistry and physical features. Ecology v.68, n.3, p.250-260. 1988.

HOWARD, J.J. Infidelity of leafcuttting ants to host plants: resource heterogenity or defense induction. Oecologia v.82, p.394-401. 1990.

HOWARD, J.J. Resource quality and cost in the foraging of leaf-cutter ants. In: HUXLEY, C.R., CUTLER, D.F. (eds.). Ants-plant interactions. Oxford: University Press, p.42-50. 1991.

MACARTHUR, R.H.; PIANKA, E.R. On the animal use of a patchy environment. Am. Nat. v.100, p.603-609. 1966.

MAJER, J. The maintenance of the ant mosaic in Ghana cocoa farms. J. Appl. Ecol. v.13, p.123-144. 1976.
SCHLINDWEIN, M.N. Repostas polimórficas de forrageio de operárias de Atta sexdens rubropilosa (Forel) em experimentos de campo. Dissertação (Mestrado) - Unesp, Rio Claro, 1991. p. 125.

SCHLINDWEIN, M.N.; FOWLER, H.G. Como as saúvas escolhem seu alvo. Ciência Hoje: 24: 68-71. 1999.

SCHOENER, T.W. Theory of feeding strategies. Ann. Rev. Ecol. Syst. v.11, p.369- 404.1971.

SHEPHERD, J.D. Trunk trial and the searching strategy of a leaf-cutter ant Atta columbica. Behav. Ecol. Sociobiol. v.11, p.77-84. 1982.

SOKAL, R.R., RÖHLF, F.J. Biometry. 3.ed. New York: Freeman. 1995, p.827.

SOUTHWOOD, T.R. Ecological methods: with particular references to study of insecties populations. London: Methuen. 1978. p.391.

THERIEN, M.; McNEIL, M. The discovery of new sources and subsequent trial formation by Acromyrmex octospinosus in Guadalupe. In: VAN De MEER, R.K., JAFFÈ, K.,CENDEÑO, A. (eds.). Applied mymercology: a world perspective. Boulder: Westview Press. p.373-371. 1990.

VASCONCELOS, H.L. Atividade forrageira, distribuição e fundação de colônias de saúvas (Atta ssp.), em floresta da amazônia central. Dissertação (mestrado) - INPA, Manaus. 1987, p.62

1990. Foraging activity of two species of leaf-cutting ants (Atta) in a primary forest of Central Amazon. Ins. Soc. v.37, n.2, p.131-145. 1990.

WILSON, E.O. 1980. Caste and division of labor in leaf-cutter ants (Hymenoptera: Formicidae: Atta) I. The overall pattern in Atta sexdens. Behav. Ecol and Sociobiol. v.2, n.2, p.143-156.1980. 


\section{Resumo:}

Com a utilização de armadilhas de solo, transplante de mudas de Citrus sinensis e árvores artificiais utilizando várias espécies de plantas foi avaliada a atividade de forrageamento de A. sexdens rubropilosa em uma área de "campo sujo". Foi analisado como as saúvas encontravam as mudas de Citrus e como se dava o corte destas plantas. Os dados mostraram que a distância do ninho e dos recursos foi o estímulo mais importante para a atividade de corte e que plantas com maior preferência, localizadas mais distantes, são cortadas em menor intensidade do que plantas com menor preferência localizadas mais próximo ao ninho e aos olheiros.

\section{Palavras-chave:}

Atta, Saúvas, Comportamento, Forrageamento, Citrus. 